\title{
BMJ Open What matters most for end-of-life care? Perspectives from community-based palliative care providers and administrators
}

\author{
Bina Mistry, ${ }^{1}$ Daryl Bainbridge ${ }^{2}$ Deanna Bryant, ${ }^{1}$ Sue Tan Toyofuku, ${ }^{3}$ \\ Hsien Seow ${ }^{2,4}$
}

To cite: Mistry B,

Bainbridge D, Bryant D, et al. What matters most for endof-life care? Perspectives from community-based palliative care providers and administrators. BMJ Open 2015;5:e007492. doi:10.1136/bmjopen-2014007492

- Prepublication history for this paper is available online. To view these files please visit the journal online (http://dx.doi.org/10.1136/ bmjopen-2014-007492).

Received 22 December 2014 Revised 8 May 2015 Accepted 8 June 2015

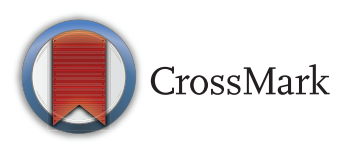

${ }^{1}$ Cancer Care Ontario, Toronto, Ontario, Canada ${ }^{2}$ Department of Oncology, McMaster University, Hamilton, Ontario, Canada ${ }^{3}$ Long Beach, California, USA ${ }^{4}$ Escarpment Cancer Research Institute, Hamilton, Ontario, Canada

Correspondence to Dr Hsien Seow, seowh@mcmaster.ca

\section{ABSTRACT}

Objectives: There has been little research conducted to understand the essential meaning of quality, community-based, end-of-life (EOL) care, despite the expansion of these services. The purpose of this study was to define what matters most for EOL care from the perspective of a diverse range of palliative care providers in the community who have daily encounters with death and dying.

Methods: We used interviews to explore the perceptions of providers and administrators from 14 specialised palliative care teams in Ontario, Canada. Participants were prompted with the question 'What matters most for EOL care? Responses were analysed using a phenomenological approach to derive themes depicting the universal essence of EOL care.

Results: Data from 107 respondents were obtained and analysed, from which 40 formulated concepts emerged; these were further grouped into 9 themes. Of the respondents, $39 \%$ were nurses, $19 \%$ physicians, $27 \%$ were supervisors or executives and $15 \%$ other. The most predominate concept was that Patient's Wishes are Fulfilled, cited by almost half the respondents. The most prominent themes were Addressing the Non-physical Needs, Healthcare Teams' Nature of Palliative Care Delivery, Patient Wishes are Honoured, Addressing the Physical Needs, Preparing for and Accepting Death, Communication and Relationship Development, and Involving and Supporting the Family.

Conclusions: 9 critical domains of EOL care evolved from the interviews, indicating that quality EOL care extends beyond managing physical pain, but includes a holistic perspective of care, a healthcare team dedicated to the EOL journey and a patient-centred pathway. Tailoring the provision of care to consider these important elements plays a critical role in supporting a positive EOL experience for patients and families.

\section{INTRODUCTION}

End-of-life (EOL) care refers to care for people with advanced disease once they have reached a point of rapid decline, typically the
Strengths and limitations of this study

- End of life presents a unique and critical segment along the healthcare trajectory.

- This study used an in-depth phenomenological approach with over 100 individuals involved in the provision of palliative care to discern the most essential considerations of end-of-life care in the community.

- Attention to traditionally medically oriented concerns, such as pain control, were cited as important, however, what emerged as even more crucial is providers' attention to patient's nonphysical needs, the delivery of care that is patient directed and the sensitivity with which care is provided, as well as care that is timely and skilled, and that addresses the needs of the family.

- A limitation of this study is that the provider perspectives captured may not be representative of those in other countries, although our findings largely correspond to key domains of quality palliative care proposed in international studies.

- The themes, identifying what matters most, provide valuable guidance towards prioritising the primary objectives of end-of-life care in the home setting.

last few weeks or months before death. ${ }^{1}$ Similar to the approach of palliative care in general, EOL care largely revolves around maintaining the quality of life and comfort of the patient, and their family, through management of pain and other physical, psychosocial and spiritual morbidities, but focusing on the defined period of time before death. ${ }^{2-}$ ${ }^{4}$ Patients at EOL can have variable complex medical issues and tend to use a high proportion of healthcare expenditures; also, the intensification of care is often associated with poorer outcomes. ${ }^{15-7}$ Accordingly, there is growing attention, globally, to enhance palliative and EOL care, especially in the home 
setting. Home is where most patients prefer to be cared for at $\mathrm{EOL}^{8}{ }^{9}$ and where care can be both high quality and more cost-effective. ${ }^{10-12}$

As with palliative care, which should begin gradually and earlier in the illness trajectory, EOL care can occur in a number of settings, such as in the patient's home, as well as in hospital intensive and palliative care units, residential hospices and long-term care facilities. Each setting of care is organised and financed to deliver care differently, based on its service mandate, professional complement and the unique care needs of the populations served. Accordingly, the extent of EOL services offered in each setting also vary. It is, therefore, important to understand potential nuances in the defining elements of quality EOL care in different healthcare settings, and from a variety of perspectives, particularly from those with vast experience in this care.

Several studies have explored the quality of EOL care from the perspectives of seriously ill patients, caregivers and families. ${ }^{13}$ These studies have identified broad lists of elements of quality. ${ }^{14-18}$ For instance, a study by Heyland $e t a l,{ }^{17}$ in which 434 hospitalised terminally ill patients were surveyed about aspects of care, revealed five top concerns rated as extremely important: trust and confidence in the physician; not to be kept alive on life support; honest communication; feelings of completion; and not being a burden on the family. Yet, asking patients or family caregivers directly 'What matters most?' only considers their individual viewpoints, at that point in time, which may be unique to the individual's preferences or change as the experience unfolds. Furthermore, much of this research has been conducted in acute care settings, such as hospitals or intensive care units, or long-term care facilities. However, less research has focused on defining quality when the patient is at home, in a non-institutional setting. As well, the perspectives of community-based palliative care providers themselves, who provide EOL care on a daily basis in multiple patients' homes, have not been extensively studied. The objective of this study was to distil the key elements of quality EOL care based on the experiences of a diverse cross-section of palliative care providers and administrators who are involved with the provision of EOL care to patients in their homes.

\section{METHODS}

Design

This is a qualitative study that used unstructured face-to-face interviews to explore the perceptions of a large selection of palliative care providers and administrators as to what is most important in EOL care. Responses were analysed using a phenomenological approach to derive themes depicting the universal essence of EOL care. Phenomenology is the appropriate method for developing a deep understanding of the common meaning of a phenomenon among multiple individuals. $^{19}$ This study received approval by the
Hamilton Health Sciences/McMaster University research ethics review board, Hamilton, Ontario, Canada.

\section{Participants and setting}

Participants were frontline and administrative staff across 14 palliative care teams in Ontario, Canada, representing rural and urban settings. We were able to include a large pool of participants to explore the diversity of perspectives, and we assume that this number led to a well saturated theory. ${ }^{19}$

Hospital-based and home-based palliative care in Ontario is covered by a universally funded healthcare programme, and is accessible throughout the dying trajectory. ${ }^{20}$ Homecare case managers assess palliative care patients' needs, and allot nursing and other homecare services and equipment as needed. Some communities in the province have specialist palliative care teams that tend to have more expertise and offer better coordination between homecare providers, family physicians and palliative care physicians, compared to usual home care. The 14 study teams we interviewed had been selected for a previous publication as exemplars of specialist palliative care teams serving patients in their homes. ${ }^{21}$

Convenience sampling methods were used to recruit individuals from each specialist team to represent the diversity of professional disciplines and roles present. The authors were familiar with the lead administrators of the teams but not with many of the providers. These leads identified other potential participants on their 'team', who were then approached by the research team to be interviewed. Within each team, different provider types were sampled-physicians, nurses, case managers (often former nurses, but who provide no direct care), service administrators, allied health professionals and others-to ensure perspectives from many persons involved in EOL care were captured. All respondents had expertise in palliative and EOL care.

\section{Data collection}

The authors conducted the interviews (the majority led by $\mathrm{DeB}$ or $\mathrm{DaB}$ ) accompanied by a note taker, who in most cases was also an author, to help ensure maximum exposure to the data. All the authors have extensive experience in interviewing, and received subsequent training, prior to the study, from an industry expert in qualitative data collection (ST). Participants were interviewed between February and August 2013. All participants were prompted with the same question, 'What matters most for EOL care?', and, when required, the interviewer followed up with probing or clarifying questions to gather deeper meanings and to explore past experiences. In addition to the open dialogue with the interviewer, participants were asked to write bullet points of their main thoughts in response to the question. The interview schedule contained other questions about care processes, reported in another publication. 
The interviews were audio recorded and the written points were photographed.

\section{Data analysis}

Interview audio files were transcribed verbatim, and corresponding written responses were added to each transcript. To facilitate the analysis process, interview transcripts were imported into NVivo Qualitative Data Analysis Software V.10 (QSR International, 2012). We analysed the transcripts using a method based on steps, described by Colaizzi, for phenomenological research. ${ }^{22}$ The process began with the primary analysts (BM and $\mathrm{DaB})$ reading each transcript multiple times. These analysts then independently coded significant statements in the transcripts and interpreted the meaning of each statement, organising the derived meanings into formulated concepts about quality of EOL care. Discrepancies in the emerging concepts between the analysts were compared and reconciled. Next, they clustered the formulated concepts into themes to extract the essential nature of what EOL care means.

The concepts and themes were discussed among the authors to reach consensus and refined as necessary, with referral back to the original transcripts for validation. Finally, an exhaustive description of the most commonly shared themes was written. Despite the study having a large sample size, careful attention was given to preserving the details of each individual's perceptions. In consideration of the focused nature of the single interview question and the number of respondents involved, which was much greater than the 3-10 participants typically found in phenomenological studies, ${ }^{19}$ we chose to include an illustration of the prevalence of concepts and themes according to their frequency of mention.

In addition to double coding and consensus making among the researchers, other steps taken to help ensure methodological rigour of the analysis included maintaining an audit trail, an external peer review process to substantiate the research process and member checking in which preliminarily findings were shared with respondents, and formally vetted in a group session with respondents and other palliative care workers. ${ }^{19}$

\section{RESULTS}

\section{Participant demographics}

A total of 107 palliative care providers and administrators, the characteristics of whom are provided in table 1 , participated in this study. We were able to capture the perceptions of all key palliative care providers in each team, with each team having a mean of eight providers interviewed. The 'what matters most' portion of the interview took between 5 and $25 \mathrm{~min}$. Respondent professions according to current role were grouped into four categories: Nurses, Executives, Physicians and Other. Palliative care teams' 'Executives' included directors, managers and team leads, and 'Other' included case managers (6), spiritual and bereavement staff (7), and data support staff (3). The largest provider-type interviewed was nurses, comprising $39 \%$ of all participants. The majority of participants had routine patient and family interactions dealing with palliative care in their current role. Over half $(58 \%)$ the study participants had been in their current role for more than 5 years.

\section{What matters most for EOL care themes}

From the interview transcripts, 477 significant statements were extracted. These statements represented 40 unique formulated concepts that define participant's perceptions of what matters most in EOL care. These concepts were further categorised into nine themes to better comprehend and relate the depth of ideas described. Table 2 shows each theme and the associated concepts. Addressing the Non-physical Needs, Healthcare Teams' Nature of Palliative Care Delivery, Patient Wishes are Honoured and Addressing the Physical Needs emerged as the most prevalent themes, mentioned by at least half the respondents. A full description of the top four themes with supporting quotes from participants is provided.

\section{Addressing the non-physical needs}

Many palliative care providers expressed that delivering good palliative care meant that when possible, all patient and caregiver needs were being met, above and beyond the management of pain. Non-physical needs were considered inclusive of supporting the spiritual and emotional journey for the patient and caregivers. In fact, some participants claimed that addressing the patient's psychosocial issues can help moderate their physical symptoms. Being free of emotional and spiritual burden, including the fear of dying, was considered critical in ensuring the patient's remaining days are mentally 'pain free'.

It's management of all of these issues, it's not just pain, it's not just nausea, it's not just shortness of breath it's this management of psycho-social struggle, the psychosocial pain and suffering that goes with dying.-Palliative Care Physician

EOL care was often described as a journey with many different stages, and within each stage, many different care needs and challenges. Providers expressed the importance of having a mutual understanding that care requirements can change from day to day, and patient's need to feel confident that their changing requirements can be met. Equally important was the concept of value for the patient and treating the patient with respect, compassion and dignity, while providing all the support that is required.

I think the way of being; compassion is key, responsiveness. It's not something that you can just wait, respect for the patient, the family, their wishes their needs, excellence in pain and symptom management, attentiveness to the 
Table 1 Participant demographics $(\mathrm{N}=107)$

\begin{tabular}{|c|c|c|c|c|c|}
\hline Participant characteristic & $\begin{array}{l}\text { Nurses } \\
\mathrm{N}=42\end{array}$ & $\begin{array}{l}\text { Executives } \\
\mathrm{N}=29\end{array}$ & $\begin{array}{l}\text { Physicians } \\
\mathrm{N}=20\end{array}$ & $\begin{array}{l}\text { Other } \\
N=16\end{array}$ & $\begin{array}{l}\text { Overall } \\
\mathrm{N}=107\end{array}$ \\
\hline Overall distribution by profession (\%) & 39 & 27 & 19 & 15 & 100 \\
\hline \multicolumn{6}{|l|}{$\operatorname{Sex}(n)$} \\
\hline Female & 40 & 29 & 9 & 12 & 90 \\
\hline Male & 2 & - & 11 & 4 & 17 \\
\hline \multicolumn{6}{|l|}{ Number of years in current role $(n)$} \\
\hline $0-5$ & 17 & 11 & 6 & 11 & 45 \\
\hline $6-10$ & 11 & 7 & 1 & 1 & 20 \\
\hline $11-15$ & 5 & 3 & 1 & - & 9 \\
\hline $16-20$ & 4 & 1 & 2 & 1 & 8 \\
\hline $21-30$ & 3 & 1 & 4 & 1 & 9 \\
\hline Unknown & 2 & 6 & 6 & 2 & 16 \\
\hline \multicolumn{6}{|l|}{ Affiliation, region or Local Health Integration Network (n) } \\
\hline $\begin{array}{l}\text { Brockville and District Hospice Palliative Care Service/South East } \\
\text { LHIN }\end{array}$ & 5 & 3 & 2 & 1 & 11 \\
\hline Cambridge Palliative Care Team & 1 & & 1 & 1 & 3 \\
\hline Central LHIN Palliative Care Team & 4 & 3 & 1 & & 8 \\
\hline Guelph Palliative Care Team & 1 & & & & 1 \\
\hline Hamilton Central (HNHB LHIN) & 2 & 7 & 1 & 2 & 12 \\
\hline Kitchener-Waterloo Palliative Care Team & 3 & & 1 & 1 & 5 \\
\hline Mississauga Halton LHIN & 3 & 3 & & 2 & 8 \\
\hline Niagara North Palliative Care Team & 2 & 2 & 1 & 2 & 7 \\
\hline Niagara West Palliative Care Team & 3 & 3 & 3 & 1 & 10 \\
\hline $\begin{array}{l}\text { Pain and Symptom Management Consultation Service (PPSMCS), } \\
\text { Champlain LHIN }\end{array}$ & 3 & 1 & 3 & & 7 \\
\hline Stedman Palliative Care Outreach Team, Brantford & 4 & 2 & 4 & 2 & 12 \\
\hline Temmy Latner Centre for Palliative Care (TLCPC) Team, Toronto & 1 & 1 & 2 & 1 & 5 \\
\hline Toronto Central LHIN & 7 & 1 & 1 & 2 & 11 \\
\hline Upper Grand Wellington Palliative Care Team & 3 & 3 & & 1 & 7 \\
\hline Total & 42 & 29 & 20 & 16 & 107 \\
\hline
\end{tabular}

spiritual needs, and support of the care giving system, the family care giving system/normal care giving system, and the professional system as well.-Spiritual Care Specialist

\section{Healthcare teams' nature of palliative care delivery}

Providers spoke strongly about the importance of being compassionate and having a healthcare team that functioned as a unit. This included ensuring that providers were on the same page about the patient's wishes and care needs, and were communicating with one another as required. This cohesiveness and continuum of care delivery and planning, ensured that patients and families were not burdened with conflicting information from different providers, or having to discuss their story over and over again. Additionally, strong palliative care teams are those that deliver timely, accessible care. Patients should not be waiting for care, and if they need help they should be aware of someone they can call at any time to get immediate support. Providers also expressed that they need to educate their patients and caregivers so that these individuals know what to expect in terms of symptoms and physical and mental states as death approaches. This includes teaching patients and caregivers how to participate in their EOL care, and giving them tools to manage when the providers are away.
From the patient's point of view, from the caregivers point of view, you create spaces where they can muster the courage to have the conversations that need to be had, you teach them how to use this drug, when this is happening this is your tool, how to give them a bath and change their bed when their still in it...like all those things that people need to be able to care for one another because they've got the caring, they just need the tools. And it's our job to give them those tools.Palliative Care Nurse

\section{Patient wishes are honoured}

An overwhelming number of participants cited the most important aspect of EOL care was ensuring that patients' wishes are being met. This concept included providing patients and families the option to choose how, when and where they want to be cared for. Part of this decision-making is helping the patient and family to understand what care options are available and accessible. Participants stated that patients and caregivers want to make decisions and have control, and that this concept goes hand-in-hand with understanding that each patient has different care needs. No single palliative care delivery process or care plan will fit each and every individual, and, therefore, to provide quality EOL 


\section{Themes and associated concepts}

1. Addressing the non-physical needs

Holistic care-spiritual, emotional and physical

Patient is supported

Patient is treated with respect

Patient is treated with dignity

Patient is in the presence of loved ones

Care aligns with the patient's cultural and religious beliefs

Patient is safe

2. Healthcare teams' nature of palliative care delivery

Accessible and provides timely care

Provides compassionate care

Collaborative

Knowledgeable and skilled

Provides high-quality care

Educates and provides information and resources

Provides continuity of care

Takes action and ownership for the patient

Involved early in the patient's journey

3. Patient's wishes are honoured

Patient's wishes are fulfilled

Death in a place of choice

Availability of residence hospice

4. Addressing the physical needs

Pain and symptom management

Patient is comfortable

5. Preparing for and accepting death

Healthcare team assists in emotionally preparing patient for a peaceful death

Creating an end-of-life care plan

Communicating expectations so that patients and families are prepared

Focus on living/quality of remaining days

Patients have hope that their remaining days will be good

Planning for the legal aspects of death

6. Communication and relationship development

Healthcare team communicates openly and in a timely manner

Healthcare team listens to patient needs, feelings and experiences

Relationship/bond formed between healthcare providers

and patient

Patient and families trust the healthcare team

Patient knows help is available and who to contact

Healthcare team creates options and choices for the

patient and family

Healthcare team is honest to patients and families

7. Involving and supporting the family

Family needs are supported

Family inclusive care

8. Understanding the patient and family experience

How the journey was experienced for the patient and family

Patient experienced good outcomes/death

9. Society and the health system have a culture of supporting palliative care

Creating the normalcy of palliative care

Palliative care valued by the healthcare system
Formulated concept mentioned within all

Respondents those for that theme (\%)

55

23

21

16

14

7

4

3

56

17

15

14

13

12

8

5

5

2

49

9

8

50

37

22

41

21

9

7

5

5

1

39

14

14
11

3 care means meeting the specific requirements of each patient under each circumstance.

It's a hard one to define I think because it's based on the client/individual as to what quality end of life means to them. It may mean 'complete pain management', it may mean 'put me to sleep at the end', it may mean 'I want to be at home with the family', it may mean 'I want to have chemo until the very end'.-Case Manager

Incorporated in the concept of honouring wishes was an emphasis on 'place of death'. Participants noted that more often than not, patients have an opinion on where they want to die and need to be informed of the 
available options. In some instances, participants spoke of experiences where they did not agree with the wishes of the patient, and yet recognised that these differences in opinion have to be respected.

So what he wanted his end of life to be was to be who he always was. He didn't want to be drugged; he wanted to be able to drink beer if he wanted too, and if the chemo made him sick that would be...you know he wanted to live however he wanted to live to the day he died.-Nurse Practitioner

\section{Addressing the physical needs}

Addressing the patient's physical needs, which encompass pain and symptom management, and ensuring the patient is comfortable at all times, was important to many of the respondents. Participants reflected on experiences when patients were in pain or physically uncomfortable, and their quality of life was significantly impacted.

You have to have good symptom control. If your pain issues and shortness of breath issues and all these other issues are not properly addressed, then obviously your psychosocial issues are never going to be addressed because the pain is going to be interfering with all other types of things.-Palliative Care Physician

Also derived from the responses was the prevailing fear of pain itself. Many providers spoke of the fear that both patients and caregivers felt due to the uncertainty of how intense the pain would become in the days ahead.

\section{Impact of respondent role on perceptions}

In examining the patterns of responses according to respondents' professional roles, no major trends are apparent. All the professional groups equally valued the importance of addressing patients' non-physical needs and patients' wishes. Some minor variation emerged in physicians more often citing the nature of palliative care delivery as important, compared to nurses.

The patient, the family and the providers all recognise that they're dealing with a chronic, progressive, life ending condition and that they have a plan, such that transitions of care as organized and planned as possible and not an afterthought. That advance care planning is done proactively, in an orderly dignified way and the patient and family's needs and expectations are fully understood and the system responds appropriately.Palliative Care Physician

Nurses, on the other hand, compared to the other professional groups, more often cited that involving the family was important, as was understanding the patient and family journey.

...preparedness and anticipation of needs and family/ patient support; I think my family needs to be supported, they need to be supported and educated, as to what to expect.-Nurse

Another difference seen was that both physicians and 'other' group respondents tended to mention concepts within the Society and the Health System have a Culture of Supporting Palliative Care theme more than the others. This theme connotes that in order to deliver good quality palliative care, it has to be supported and valued by the healthcare system.

\section{DISCUSSION}

This study applied a phenomenological approach to derive a deep understanding of what matters most for EOL care from the perspective of providers and administrators experienced in palliative care. The most predominate concept, mentioned by almost half the respondents, was that the Patient's wishes are fulfilled. This corresponds to a patient-centred approach at EOL, where quality care is not only managing symptoms but, as well, supporting patients to die in the way they desire. Honouring patient wishes includes identifying what a patient wants through open communication and EOL care planning, providing education about options and realistic expectations, and allowing patients to have control over decision-making. To our knowledge, this is the largest study focused on defining EOL care quality from the perspective of a diverse group of palliative care providers working specifically in the home, a setting that is gaining more policy attention for provision of EOL care.

Most participants did not limit their responses to a single theme, but provided multiple themes that they felt were equally important, and sometimes included different aspects of care. In fact, many of the respondents (21\%) stated explicitly that EOL care must embody a multifactorial approach. It was commonly expressed that focusing care exclusively on a single need, for example, good symptom management, is not enough to drive quality. Rather, respondents stated that all patient needs be considered, whether it is pain management, spiritual support, having a responsive healthcare team, or dying at home. Furthermore, study participants stressed that depending on the patient, family and/or circumstance experienced, the most important aspects of quality EOL care can change throughout the care journey, a concept that has been identified in previous studies. ${ }^{17} 2324$ This emphasises the multifactorial and dynamic nature of palliative care.

Participants' responses more often related to the themes of Addressing the Non-Physical Needs and the Nature of Palliative Care Delivery than Addressing the Physical Needs. Pain and symptom management figures prominently in the palliative care literature, ${ }^{25-28}$ and yet only about a third of respondents $(35 \%)$ mentioned this function. Although pain management is undoubtedly critical at EOL, the respondents indicated that patients' emotional and spiritual pain can be more overwhelming than 
physical pain, and that patients who received spiritual and emotional support were often able to obtain a sense of closure. It is apparent from our findings that quality EOL care extends beyond managing the physical pain, which is often the primary focus of providers; indeed, quality also includes a holistic perspective of care, psychospiritual needs and a dedicated healthcare team.

Although the patient was the focus of most of the statements made by respondents, certain emerging concepts invoked both the patient and the family as the unit of care, specifically those concepts relating to facilitating preparedness, establishing trust and providing care options. Also, over a third of respondents distinctly mentioned involving and supporting the family. Some minor variations in the inclusion of family in the conceptualisations of what matter most were found according to professional role; perceptions that may be related to the typical nature, intensity and setting of patient interactions for a given role. In particular, the nurses were more likely to allude to the impact of EOL on the informal care providers and family. This trend may be attributed to more one-on-one time in patients' homes and with family members. As a result, this lends to more time building relationships, understanding burden and/or needs beyond those of the patient, and ultimately the perceived importance of considering the family members throughout the EOL journey.

The domains proposed by other studies focused on institutional settings are largely congruent to our findings in the home setting. A recent study by Vedel $e t a l^{18}$ in France, asked 61 palliative care patients, caregivers and providers structured questions as to whether specified elements of care are important to them. The researchers found four major critical dimensions of quality palliative care: comprehensive support for the patients; clinical management including pain control; involvement of families; and the care provided to the imminently dying person. Similarly, a review of quality death and dying research by Hales $e t a l,{ }^{13}$ of patient and provider perspectives, concluded that this is a subjective and multidimensional phenomenon represented by physical, psychological, social and spiritual experiences, as well as the nature of healthcare, life closure and death preparation, and the circumstances of death.

A major limitation of our study is that we did not directly include the perspectives of patients or family caregivers. Other studies have found that providers tend to place the greatest importance on process of care and symptom treatment, whereas patients want to be comfortable but may also have concerns that are more existential in nature. ${ }^{13} 1829$ Further, it is possible that the perspectives captured here may be different in other countries and cultures. Of note, many of the respondents are solely involved in specialised palliative care services that support patients in the home, services that not always available to all EOL patients in Ontario or elsewhere. Underpinning the perceptions reported is that enhanced services beyond conventional homecare are adequately resourced and accessible for those nearing death, although many of the respondents also have current and previous experiences in usual care and institutional settings. A methodological strength was that we included a large sample of over 100 experienced and diverse providers of palliative care, with numerous patient and caregiver experiences to draw from. The respondents were able to reflect on what matters most, and quality care based on entire EOL journeys, considering the changing needs of patients throughout their trajectory of care. Importantly, we did not query respondents with a preconceived list of care domains, unlike other studies, ${ }^{17} 183031$ but instead allowed themes to emerge naturally.

\section{CONCLUSION}

Nine critical domains of EOL care evolved from the interviews with the large cross-section of palliative care providers serving home settings. Many of the themes we found correspond to the broader findings of previous research $^{13} 1^{18}$ and palliative care's best practice elements employed in many countries. ${ }^{25}$ The contribution that our study makes is in denoting which elements of EOL are the most essential: quality EOL care extends beyond managing physical pain, but includes a holistic perspective of care, a healthcare team both dedicated and flexible to accompanying their patients and families on this journey, and is patient centred. Resourcing and building palliative care programmes that embody these philosophies play a crucial role in supporting a positive EOL experience for patients and families.

Acknowledgements The authors wish to acknowledge the Ontario Ministry of Health and Long-Term Care, which provided funding for this study.

Contributors DaB, DeB, STT and HS were responsible for the study design. All authors were involved in data collection and analysis. BM, DaB and HS were responsible for the drafting of the manuscript. All authors were involved in editing the final manuscript.

Funding Funding for this study was received from the Ontario Ministry of Health and Long-Term Care.

Competing interests None declared.

Ethics approval Hamilton Health Sciences/McMaster University research ethics review board.

Provenance and peer review Not commissioned; externally peer reviewed.

Data sharing statement No additional data are available.

Open Access This is an Open Access article distributed in accordance with the Creative Commons Attribution Non Commercial (CC BY-NC 4.0) license, which permits others to distribute, remix, adapt, build upon this work noncommercially, and license their derivative works on different terms, provided the original work is properly cited and the use is non-commercial. See: http:// creativecommons.org/licenses/by-nc/4.0/

\section{REFERENCES}

1. Watson M, Lucas C, Hoy A, et al. Oxford handbook of palliative care. New York: Oxford University Press, 2005.

2. Genet N, Boerma WG, Kringos DS, et al. Home care in Europe: a systematic literature review. BMC Health Serv Res 2011;11:207.

3. Shaw KL, Clifford C, Thomas K, et al. Review: improving end-of-life care: a critical review of the gold standards framework in primary care. Palliat Med 2010;24:317-29.

4. Davies E, Higginson IJ. Palliative care: the solid facts. Copenhagen, Denmark: World Health Organization, 2004. 
5. Coyle N. Interdisciplinary collaboration in hospital palliative care: chimera or goal? Palliat Med 1997;11:265-6.

6. van den Beuken-van Everdingen MH, de Rijke JM, Kessels AG, et al. Quality of life and non-pain symptoms in patients with cancer. $J$ Pain Symptom Manage 2009;38:216-33.

7. Zhang B, Wright AA, Huskamp HA, et al. Health care costs in the last week of life: associations with end-of-life conversations. Arch Intern Med 2009;169:480-8.

8. Brazil K, Howell D, Bedard M, et al. Preferences for place of care and place of death among informal caregivers of the terminally ill. Palliat Med 2005; 19:492-9.

9. Gomes B, Calanzani N, Gysels M, et al. Heterogeneity and changes in preferences for dying at home: a systematic review. BMC Palliat Care 2013;12:7.

10. Candy B, Holman A, Leurent B, et al. Hospice care delivered at home, in nursing homes and in dedicated hospice facilities: a systematic review of quantitative and qualitative evidence. Int $J$ Nurs Stud 2011;48:121-33.

11. Higginson IJ, Evans CJ. What is the evidence that palliative care teams improve outcomes for cancer patients and their families? Cancer J 2010;16:423-35.

12. Seow $H$, Bainbridge $D$, Bryant $D$. Palliative care programs for patients with breast cancer: the benefits of home-based care. Breast Cancer Manag 2013;2:407-16.

13. Hales S, Zimmermann C, Rodin G. The quality of dying and death Arch Intern Med 2008;168:912-18.

14. Burge $F$, Lawson $B$, Johnston $G$, et al. Bereaved family member perceptions of patient-focused family-centred care during the last 30 days of life using a mortality follow-back survey: does location matter? BMC Palliat Care 2014;13:25.

15. Field MJ, Cassel CK. Approaching death: improving care at the end-of-life. Washington DC: Institute of Medicine, National Academy Press, 1997.

16. Hearn J, Higginson IJ. Development and validation of a core outcome measure for palliative care: the palliative care outcome scale. Palliative Care Core Audit Project Advisory Group. Qual Health Care 1999;8:219-27.

17. Heyland DK, Dodek P, Rocker G, et al. What matters most in end-of-life care: perceptions of seriously ill patients and their family members. CMAJ 2006;174:627-33.

18. Vedel I, Ghadi V, Lapointe L, et al. Patients', family caregivers', and professionals' perspectives on quality of palliative care: a qualitative study. Palliat Med 2014;28:1128-38.
19. Creswell J. Qualitative inquiry and research design: choosing among five traditions. 3rd edn. Thousand Oaks, CA: Sage Publications, 2013.

20. Ontario Ministry of Health and Long-Term Care. Ministry Programs: Ontario Health Insurance Plan (OHIP). 2012. http://www.health.gov. on.ca/en/public/programs/ohip/

21. Seow H, Brazil K, Sussman J, et al. Impact of community based, specialist palliative care teams on hospitalisations and emergency department visits late in life and hospital deaths: a pooled analysis. BMJ 2014;348:g3496.

22. Colaizzi PF. Psychological research as a phenomenologist views it. In: Valle RS, King M eds. Existential phenomenological alternatives for psychology. New York: Oxford University Press, 1978:48-71.

23. Brom L, Pasman HR, Widdershoven GA, et al. Patients' preferences for participation in treatment decision-making at the end of life: qualitative interviews with advanced cancer patients. PLOS ONE 2014;9:e100435.

24. Fitzsimons D, Mullan D, Wilson JS, et al. The challenge of patients' unmet palliative care needs in the final stages of chronic illness. Palliat Med 2007;21:313-22.

25. Barazzetti G, Borreani C, Miccinesi G, et al. What "best practice" could be in Palliative Care: an analysis of statements on practice and ethics expressed by the main Health Organizations. BMC Palliat Care 2010;9:1.

26. Caraceni A, Cherny N, Fainsinger R, et al. Pain measurement tools and methods in clinical research in palliative care: recommendations of an Expert Working Group of the European Association of Palliative Care. J Pain Symptom Manage 2002;23:239-55.

27. van den Beuken-van Everdingen MH, de Rijke JM, Kessels AG, et al. Prevalence of pain in patients with cancer: a systematic review of the past 40years. Ann Oncol 2007;18:1437-49.

28. Davies E, Higginson IJ. Better palliative care for older people. Copenhagen, Denmark: World Health Organization, 2004.

29. Hirai K, Miyashita M, Morita T, et al. Good death in Japanese cancer care: a qualitative study. J Pain Symptom Manage 2006;31:140-7.

30. Kim S, Lee Y. Korean nurses' attitudes to good and bad death, life-sustaining treatment and advance directives. Nurs Ethics 2003;10:624-37.

31. Rietjens JA, van der Heide A, Onwuteaka-Philipsen BD, et al. Preferences of the Dutch general public for a good death and associations with attitudes towards end-of-life decision-making Palliat Med 2006;20:685-92. 